\title{
Analisis Kelimpahan dan Identifikasi Predator Abalon (Haliotis squamata) di Pantai Geger, Nusa Dua, Bali.
}

\author{
Jefry Cristian Bulan $^{a}$, I Gede Hendrawan ${ }^{a^{*}}$, Ni Luh Putu Ria Puspitha ${ }^{a}$ \\ ${ }^{a}$ Program Studi Ilmu Kelautan, Fakultas Kelautan dan Perikanan, Universitas Udayana, Bali, Indonesia \\ *Corresponding author email : gede.hendrawan@unud.ac.id
}

\section{ARTICLE INFO}

\section{ABSTRACT}

\section{Article history:}

Received: January $07^{\text {th }} 2019$

Received in revised form: February $19^{\text {th }} 2029$

Accepted: May $23^{\text {th }} 2019$

Available online: February $28^{\text {th }} 2020$
Keywords:

Abalone

Predator

Geger Beach

Abundance

\begin{abstract}
This research was conducted at Geger Beach, Nusa Dua, Bali for 30 days. The purpose of this study was to determine type and abundance of abalone predators at potential abalone culture area in Geger Beach, Nusa Dua, Bali. The method was Underwater Visual Census by using belt transects with a length of 50 meters with a distance of 2.5 meters left and 2.5 meters at the right side with a total area of $250 \mathrm{~m}^{2}$. This research was conducted at three different areas which are point 1 , point 2 , and point 3 . A drum was placed in each area where the camera was set to be closely observed the predators approching the abalones. The results of this study showed the predator of the abalone found in drum \& transect area, morey eels Gymnothorax thyrsoideus and Ephinephelus sp. The results of predator abundance at point 1 were 0.0053 individuals $/ \mathrm{m}^{2}$ for Gymnhotorax thyrsoideus and 0.0013 individual $/ \mathrm{m}^{2}$ for Epinephelus sp, at point 2 it was 0.013 individuals $/ \mathrm{m}^{2}$ for Gymnhotorax thyrsoideus and 0.040 individuals $/ \mathrm{m}^{2}$ for Epinephelus $\mathrm{sp}$, at point 30.027 individuals $/ \mathrm{m}^{2}$ for Gymnhotorax thyrsoideus and 0.0013 individual $/ \mathrm{m}^{2}$ for Epinephelus sp.
\end{abstract}

2020 JMRT. All rights reserved

\section{Pendahuluan}

Abalon adalah moluska yang dapat hidup diseluruh perairan laut dunia. Abalon dapat ditemukan pada perairan dangkal hingga perairan dalam hingga mencapai kedalaman $90 \mathrm{~m}$ (Setyono, 2010). Abalon memiliki sekitar 100 spesies di dunia, 7 spesies diantaranya berada di perairan Indonesia antara lain Haliotis asnina, Haliotis varia, Haliotis squamata, Haliotis ovina, Haliotis glabra, Haliotis planate dan Haliotis crebrisculpta (Setyono, 2010). Habitat alami abalon terdapat pada daerah perairan yang berbatu serta bersembunyi di celahcelah karang dan lubang berbatu. Daerah persebaran abalon di dunia dapat ditemukan disepanjang perairan barat Amerika Utara, pantai bagian timur dan selatan Asia, Samudra Pasifik termasuk Australia dan New Zealand, Afrika dan Eropa (Setyono, 2009).

Di Indonesia, abalon tersebar pada perairan Indonesia Timur termasuk di Sulawesi Selatan, Sulawesi Utara, Sulawesi Tenggara, Maluku, dan Papua. Berbagai daerah lainnya juga merupakan daerah persebaran abalon diantaranya Kepulauan Seribu, Madura, Sumbawa, Flores, Lombok dan Bali, dan merupakan daerah tangkapan abalon (Setyono, 2010). Di Bali sendiri abalon telah dibudidayakan, salah satunya yaitu pada wilayah perairan Pantai Geger. Pantai Geger sendiri merupakan salah satu daerah pesisir pantai di Bali. Pantai ini terletak di Desa Adat Peminge, Kelurahan Benoa, Kecamatan Kuta Selatan, Kabupaten Badung (Artadana, 2017).

Penelitian mengenai abalon sebelumnya telah dilakukan oleh Hayati (2017) di Pantai Geger Nusa Dua Bali. Hasil dari penelitian budidaya abalon tersebut menunjukkan bahwa tingkat kelulusan hidup abalon mencapai 83,3\%-97,5\%. Faktor penyebab tingkat kelulusan hidup tidak mencapai $100 \%$ diduga karena faktor adanya predator. Faturrahman et al. (2015) menyatakan bahwa sesuai dengan tipe habitatnya, setiap jenis abalon akan terancam dengan predator yang berbeda-beda. Abalon yang masih muda yang menempati perairan dangkal biasanya akan diserang oleh predator dari jenis-jenis siput karnivora, kepiting, gurita dan jenis ikan karang seperti kerapu, sedangkan untuk jenis kerang abalon dewasa biasanya dimakan oleh predator dari jenis karnivora (kerapu, kakap, pari), udang karang (lobster), morey eel dan bintang laut.

Predator abalon tersebut memiliki kebiasaan makan pada waktu berbeda-beda sehingga pemangsaan bisa terjadi pada pagi, siang ataupun malam hari. Perbedaan tersebut kemungkinan besar dipengaruhi oleh beberapa faktor salah satunya pasang surut pada daerah pesisir. Pertumbuhan biota laut di daerah pasang surut sangat tinggi, hal tersebut dapat disebabkan karena daerah ini merupakan tempat hidup, tempat berlindung, dan tempat mencari makan. Selain itu, kondisi lingkungan pada daerah ini sangat menguntungkan bagi pertumbuhan biota laut karena adanya dukungan dari faktor fisika, kimia, dan biolog laut (Rumahlatu et al., 2008). Selain hal tersebut, Riyanto et al. (2016) menyatakan bahwa pola migrasi ikan karang yang mayoritas merupakan predator abalon bergerak mengikuti arah pasang surut. Pada saat pasang, ikan lebih cenderung berenang ke arah pantai mengikuti arus dan pada saat surut ikan lebih cenderung berenang mengikuti arus menjauhi pantai. Hal tersebutlah yang menjadikan kecendrungan ikan berada lebih banyak di daerah 
pesisir ketika terjadi pada saat surut menuju pasang. Beberapa predator abalon menurut teori dan penelitian diantaranya ikan karang (ikan kerapu, ikan kakap, ikan napoleon, ikan pari), udang karang, moray eel, bintang laut, dan gurita (Setyono, 2010).

Berbagai predator tersebut kemungkinan besar terdapat di wilayah perairan Pantai Geger, Nusa Dua, Bali. Hal ini dikarenakan terdapat ekosistem lamun dan terumbu karang yang ada di wiliyah tersebut. Mengingat banyaknya organisme yang ada di perairan pantai dan kemungkinan besar terdapat banyak jenis predator yang berada di wilayah tersebut, sehingga perlu untuk dilakukan penelitian lebih lanjut mengenai analisis kelimpahan dan identifikasi predator abalon di Pantai Geger, Nusa Dua, Bali.

\section{Metode}

\subsection{Waktu dan Lokasi Penelitian}

Penelitian ini dilaksanakan selama 30 hari di Pantai Geger, Nusa Dua, Kabupaten Badung, Provinsi Bali. Penentuan stasiun pengamatan dilakukan secara Random Sampling dengan jarak 40 meter antar lokasi. Pengambilan data lapangan pada area pengamatan drum abalon dilakukan selama 30 kali dengan 1 kali pengambilan data pada tiap harinya selama 30 hari dan untuk pengambilan data predator dengan metode transek dilakukan selama 3 kali yang diambil pada awal penelitian, pertengahan dan diakhir penelitian.

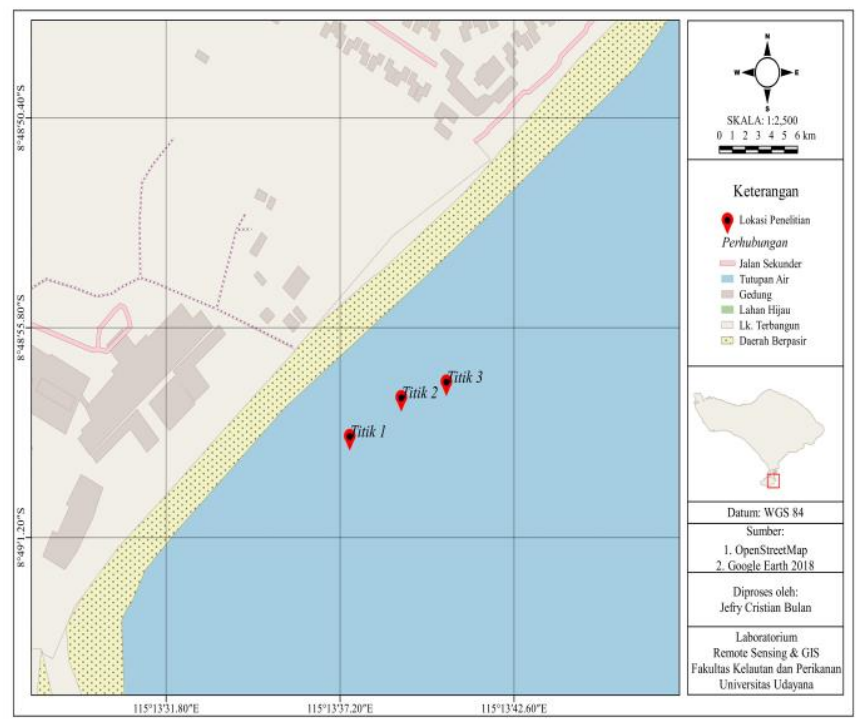

Gambar 1. Lokasi Penelitian

\subsection{Alat dan Bahan}

Alat yang digunakan dalam penelitian ini adalah GPS (Garmin), Alat Dasar Selam, Kamera, Alat tulis, Drum, Jaring (waring), dan Besi. Bahan yang digunakan pada penelitian ini menggunakan Abalon Haliotis squamata 120 ekor yang dibagi kedalam 3 drum abalon.

\subsection{Kontruksi Drum Abalon}

Struktur tempat drum abalon memiliki panjang sekitar 90 $\mathrm{cm}$ dengan diameter $60 \mathrm{~cm}$ dan ditempatkan pada dasar perairan (Dedi, 2017). Struktur drum tersebut berfungsi sebagai media dari tempat tinggal abalon. Terdapat beberapa lubang kecil pada sisi drum digunakan agar sirkulasi air dapat masuk sehingga tidak mudah terbawa arus. Selain itu pemberat juga ditambahkan agar drum sebagai tempat dari abalon dapat ditenggelamkan dengan mudah di dasar laut (Dedi, 2017). Di bawah drum terdapat kerangka besi yang disambungkan dengan drum untuk memperkuat kontruksi agar tidak mudah terbawa arus. Jumlah drum terdapat 3 buah dengan ukuran yang sama dan dengan bahan yang sama.

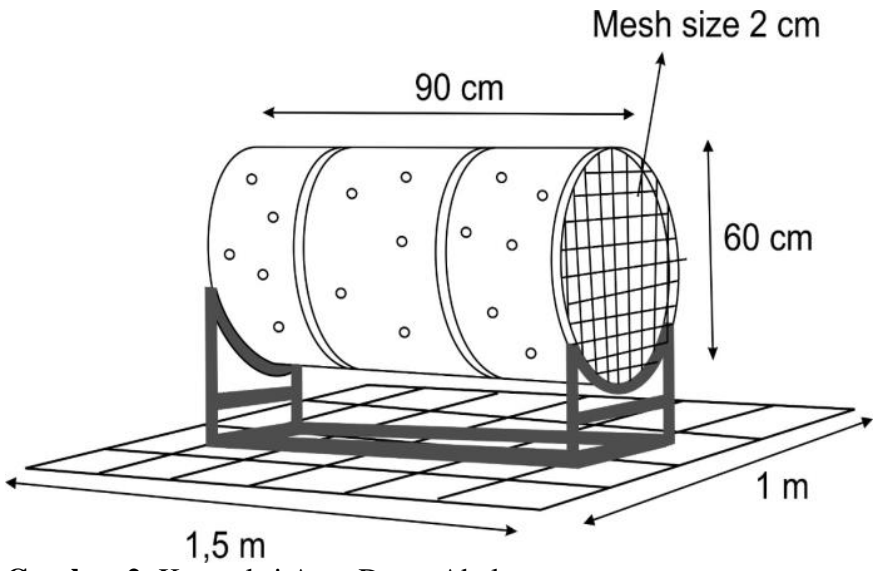

Gambar 2. Kontruksi Area Drum Abalon

Drum tersebut diisi abalon dengan jumlah tebar 40 ekor abalon/drum dengan ukuran rata-rata mencapai $3 \mathrm{~cm}$ sampai $6 \mathrm{~cm}$. Drum abalon tersebut menggunakan tutup jaring atau waring dengan ukuran mata jaring $2 \mathrm{~cm}$. Hal ini dilakukan agar abalon tidak dapat keluar dari drum. Pada saat pengambilan data, penutup jaring akan dibuka agar predator lebih leluasa untuk masuk ke dalam tempat tinggal abalon Haliotis squamata tersebut. Selain itu, sisi dalam drum abalone ditempatkan sebuah kamera bawah laut untuk membantu perekaman pemangsaan abalon yang terjadi di dalam area drum abalon.

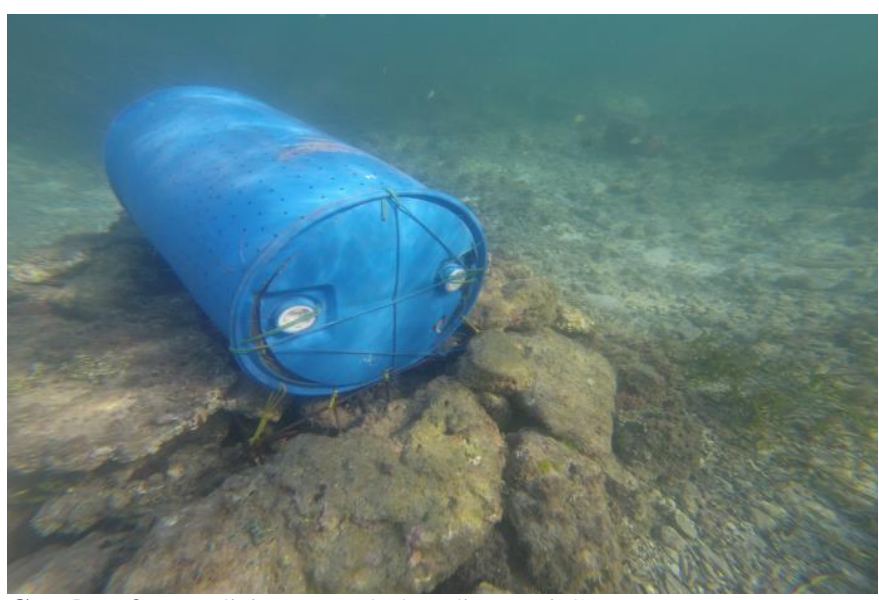

Gambar 3. Kondisi Drum Abalon di Pantai Geger

\subsection{Pengambilan Data Kelimpahan dan Identifikasi Predator Abalon}

Pengambilan data primer dilakukan secara insitu (observasi langsung di lapangan) yaitu pengamatan dan pencatatan predator abalon yang dianalisis kelimpahannya dan juga melakukan identifikasi lebih lanjut mengenai jenis dari predator abalon tersebut. Pengambilan data dilakukan menggunakan metode UVC (Underwater Visual Census) yang dikembangkan oleh English et al. (1997). Metode tersebut dibantu dengan belt transect sepanjang 50 meter dengan jarak jangkauan pengamatan di sisi kiri 2,5 meter dan sisi kanan 2,5 
meter sehingga memiliki luasan $250 \mathrm{~m}^{2}$. Metode tersebut dibantu dengan kamera bawah air untuk menghitung kelimpahan dan identifikasi predator di sepanjang transek.

Penambahan kamera bawah air juga ditempatkan pada wadah area drum abalon pada 3 titik lokasi yang berbeda untuk mengamati kejadian pemangsaan abalon dengan durasi 2 jam yang dilakuakan pada saat surut menuju pasang. Hal ini sesuai dengan Riyanto et al. (2016) menyatakan bahwa pada saat pasang ikan predator lebih cenderung berenang ke arah pantai mengikuti arus sehingga pada saat surut menuju pasang ikan tersebut banyak terdapat di area dekat pantai. Hal tersebutlah yang menjadikan pengambilan data mengenai kejadian pemangsaan akan dilakukan dan kemudian akan dilakukan reidentifikasi pada jenis predator yang telah didokumentasikan menggunakan kamera bawah laut dengan menggunakan buku identifikasi dari Setiawan (2010).

\subsection{Analisis Data}

\section{a. Kelimpahan Predator Abalon}

Kelimpahan merupakan banyaknya individu suatu organisme persatuan luas daerah pengamatan. Kelimpahan yang dihitung dalam penelitian ini adalah kelimpahan predator (Odum, 1993). Kelimpahan suatu organisme dapat dirumuskan sebagai berikut:

$N=\frac{n i}{A}$

Dimana: nilai $N$ merupakan kelimpahan organisme abalon dengan satuan (individu $/ \mathrm{m}^{2}$ ), nilai $n i$ merupakan jumlah individu predator abalon jenis ke-i, dan nilai $A$ adalah luas area pengamatan $\left(\mathrm{m}^{2}\right)$

\section{b. Frekuensi Kehadiran Predator Abalon}

Menurut Odum (1994), frekuensi kehadiran merupakan nilai yang menyatakan jumlah kehadiran suatu spesies sampling plot. Krebs (1995) dalam Ardina (2016) menyatakan bahwa data ikan yang diperoleh nilai frekuensi kehadirannya dengan menggunakan persamaan sebagai berikut:

FK $=\frac{\text { Jumlah } \text { trsnsek } \text { yang ditempati suatu jenis }}{\text { Jumlah total transek }} \times 100 \%$

Dimana: nilai FK atau frekuensi kehadiran dari jumlah transek yang ditempati suatu jenis dibagi jumlah total transek dikali $100 \%$. Kategori dalam frekuensi kehadiran dengan nilai $0-25 \%=$ sangat jarang, $25-50 \%=$ jarang, $50-75 \%=$ sering, dan $>75=$ sangat sering

\section{c. Sintasan Abalon}

Sintasan atau presentase kelangsungan hidup abalon Haliotis squamata selama penelitian dilakukan. Menurut Effendie (1979) dalam Susanto (2010) untuk mengetahui presentase sintasan abalon pada akhir penelitian menggunakan rumus:

$\mathrm{S}=\frac{\mathrm{Nt}}{\mathrm{No}} \times 100$
Dimana: nilai S adalah sintasan abalon (\%), nilai Nt adalah jumlah akhir percobaan (ekor), dan $\mathrm{N}$ adalah jumlah awal percobaan (ekor)

\section{Hasil}

\subsection{Jenis Predator dan non-predator abalon Haliotis squamata}

Tabel 1. Organisme yang masuk dalam area drum abalon Haliotis squamata

\begin{tabular}{|c|c|c|c|c|c|}
\hline \multirow[t]{2}{*}{ Jenis Organisme } & \multirow{2}{*}{$\begin{array}{l}\text { Non- } \\
\text { Preda } \\
\text { tor }\end{array}$} & \multicolumn{3}{|c|}{ Jumlah Kehadiran } & \multirow{2}{*}{$\begin{array}{l}\text { FK } \\
(\%)\end{array}$} \\
\hline & & 1 & 2 & 3 & \\
\hline Ctenochaetus binotatus & $\checkmark$ & 65 & 79 & 13 & 100 \\
\hline Ctenochaetus striatus & $\checkmark$ & 36 & 78 & 4 & 100 \\
\hline Apogon moluccensis & $\checkmark$ & 13 & 115 & 0 & 66,67 \\
\hline Canthigaster papua & $\checkmark$ & 8 & 2 & 2 & 100 \\
\hline Abudefduf sexfasciatus & $\checkmark$ & 136 & 216 & 11 & 100 \\
\hline Abudefduf vaigiensis & $\checkmark$ & 56 & 135 & 8 & 100 \\
\hline Chaetodon decussatus & $\checkmark$ & 14 & 9 & 5 & 100 \\
\hline $\begin{array}{l}\text { Dendrochirus } \\
\text { brachypterus }\end{array}$ & $\checkmark$ & 0 & 0 & 1 & 33,33 \\
\hline Ostracion cubicus & $\checkmark$ & 0 & 0 & 1 & 33,33 \\
\hline Dascyllus trimaculatus & $\checkmark$ & 0 & 12 & 0 & 33,33 \\
\hline Pomacanthus imperator & $\checkmark$ & 0 & 27 & 26 & 66,67 \\
\hline Gymnothorax thyrsoideus & & 7 & 39 & 0 & 66,67 \\
\hline
\end{tabular}

Berdasarkan hasil penelitian (Tabel 1) menunjukan bahwa organisme predator dan non-predator yang ditemukan sebanyak 12 jenis dengan Frekuensi kehadiran yang ditempatkan pada ketiga titik tersebut memiliki rentang kehadiran yakni berkisar 33,33\% - 100\%. Predator yang ditemukan pada hasil penelitian ini adalah Gymnothorax thyrsoideus yang telah ditemukan dalam area drum abalon Haliotis squamata. Menurut Fishbase (2018) distribusi Gymnothorax thyrsoideus tersebar di daerah Indo-Pasifik. Ikan jenis Gymnothorax thyrsoideus biasa disebut belut laut atau moray eel. Menurut Setyono (2010) belut laut atau moray eel termasuk kedalam predator utama bagi abalon baik abalon muda maupun dewasa. Dilihat dari hasil penelitian ini Gymnothorax thyrsoideus memiliki frekuensi kehadiran mencapai 66,67\% yang dikategorikan sering (Ardina, 2016). Hal ini memungkinkan adanya potensi penyerangan ataupun pemangsaan yang lebih sering terhadap abalon Haliotis squamata. Pembuktian dilakukan melalui kamera pengamatan (Gambar 4) bahwa, ikan jenis Gymnothorax thyrsoideus tersebut melakukan penyerangan terhadap abalon Haliotis squamata. Hal tersebut tergambar jelas pada gambar 4 bahwa jenis Gymnothorax thyrsoideus melakukan penyerangan terhadap abalon Haliotis squamata. Hal tersebut didukung pernyataan National Oceanic and Atmospheric Administration (2008) bahwa keluarga dari muridae atau biasa disebut belut laut merupakan predator utama bagi abalon. 


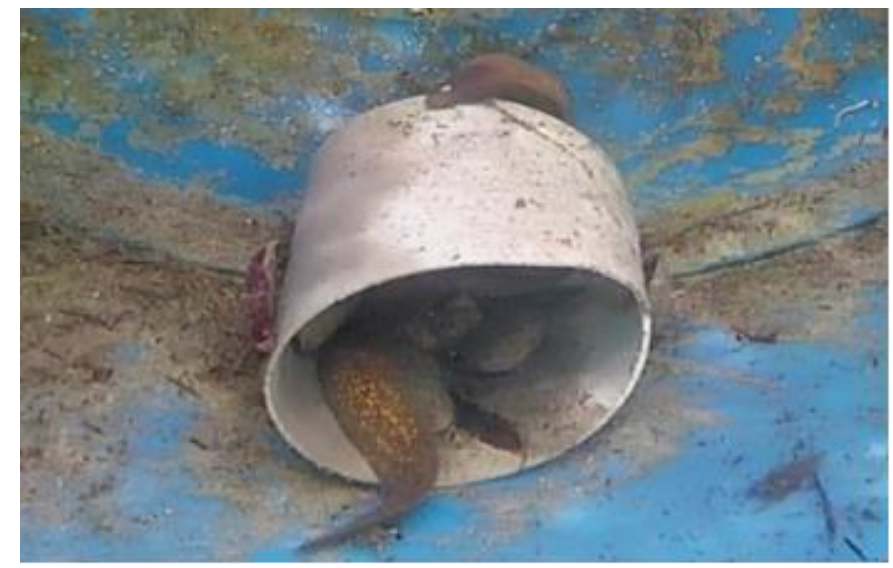

Gambar 4. Predator Abalon Haliotis squamata

\subsection{Kelimpahan Predator Abalon Haliotis squamata}

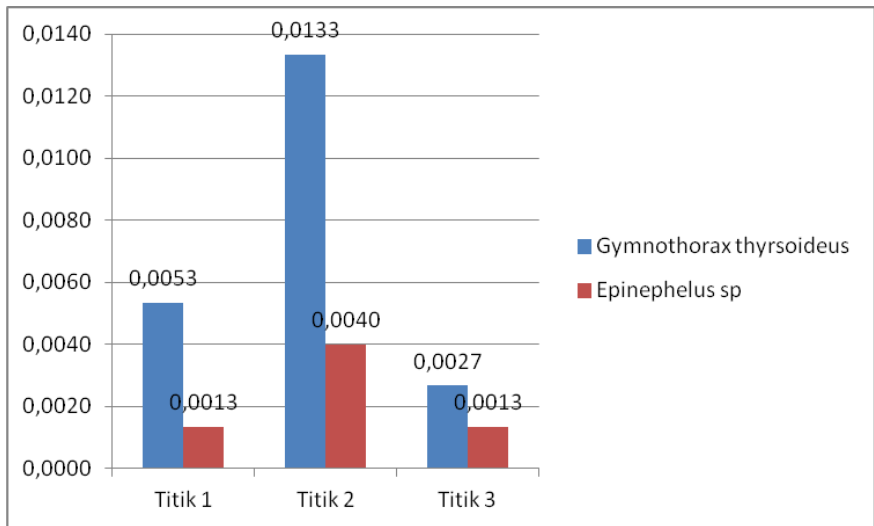

Gambar 5. Kelimpahan predator abalon Haliotis squamata

Pada penelitian ini data yang dihasilkan berupa data kelimpahan rata-rata predator abalon Haliotis squamata pada daerah transek. Dari hasil ketiga titik tersebut hanya dua jenis yang dapat dikategorikan sebagai predator yakni Gymnhotorax thyrsoideus dan Epinephelus sp. Pada titik yang pertama menunjukan data kelimpahan yakni sebesar 0,0053 individu $/ \mathrm{m}^{2}$ untuk jenis Gymnhotorax thyrsoideus dan untuk jenis Epinephelus sp memiliki nilai sebesar 0,0013 individu $/ \mathrm{m}^{2}$. Pada titik 2 Gymnhotorax thyrsoideus memiliki nilai 0,0133 individu $/ \mathrm{m}^{2}$ dan Epinephelus $s p$ memiliki nilai 0,040 individu $/ \mathrm{m}^{2}$. Pada titik 3 Gymnhotorax thyrsoideus memiliki nilai 0,027 individu $/ \mathrm{m}^{2}$ dan Epinephelus sp memiliki nilai 0,0013 individu $/ \mathrm{m}^{2}$. Hal tersebut menjadikan titik 2 sebagai nilai kelimpahan predator abalon yang paling tertinggi. Hal tersebut dikarenakan daerah tersebut merupakan daerah terumbu karang yang merupakan daerah habitat ikan-ikan dan organisme lainnya. Predator yang paling terendah ada pada titik 3. Hal ini diduga karena pada titik tersebut memiliki daerah yang jauh dengan ekosistem terumbu karang. Hal tersebut diperkuat dengan pernyataan Rani (2003) bahwa terumbu karang memberikan beberapa fungsi ekologi terhadap biota laut (ikan dan invertebrata), yaitu sebagai daerah pemijahan, daerah pembesaran, dan daerah mencari makan.

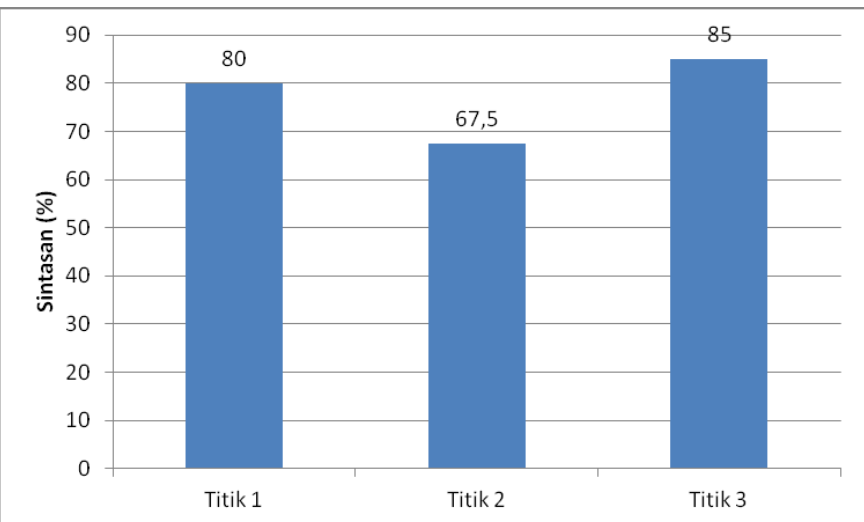

Gambar 6. Kelimpahan predator abalon Haliotis squamata

Berdasarkan hasil (Gambar 6) sintasan yang diperoleh pada ketiga stasiun yaitu titik 1, titik 2, dan titik 3 pada Pantai Geger, Nusa Dua, Bali. Hasil sintasan pada ketiga stasiun tidak terdapat sintasan yang mencapai $100 \%$. titik 1 menunjukan nilai sintasan yang cukup tinggi yaitu $80 \%$. Pada hasil titik 2 memiliki sintasan cukup rendah yaitu $67,5 \%$. Hasil stasiun lainnya yaitu pada titik 3 menunjukan nilai sintasan $85 \%$. Sintasan paling tinggi di Pantai Geger, Nusa Dua, Bali ada pada titik 3 dengan nilai $85 \%$. Nilai sintasan terendah ada pada stasiun 2 bernilai $67,5 \%$. Hal ini sesuai dengan kelimpahan predator abalon pada Gambar 5, dimana kelimpahan predator tertinggi terdapat pada titik 2. Hal tersebut didukung oleh pernyataan Dedi (2016) bahwa faktor yang mempengaruhi sintasan adalah predator yang masuk dalam wadah pemeliharaan seperti kepiting dan ikan ikan kecil yang menyebabkan kematian abalon. Pada penelitian ini predator yang ditemukan pada Pantai Geger Nusa Dua, Bali adalah morey (Gymnothorax thyrsoideus). Menurut Setyono (2009) jenis predator yang menyerang abalon adalah jenis ikan karnivora (kerapu, pari, kakap), morey, gurita, udang karang dan bintang laut.

\section{Kesimpulan}

Berdasarakan hasil penelitian terdapat 2 jenis predator abalon Haliotis squamata yang ditemukan di Pantai Geger yaitu Gymnothorax thyrsoideus dan Epinephelus sp, dengan kelimpahan paling banyak pada morey Gymnothorax thyrsoideus.

\section{Daftar Pustaka}

Artadana IW. 2017. Daya Dukung Kawasan (DDK) wisata pantai di pantai Geger, kelurahan Benoa, kecamatan Kuta Selatan, kabupaten Badung, Bali [Skripsi]. Bali: Fakultas Kelautan dan Perikanan, Universitas Udayana. 47 hal

Ardina WO, Nadia LOAR, Abdullah. 2016. Studi keanekaragaman jenis ikan demersal yang berasosiasi pada Apartemen Ikan di perairan laut Kabupaten Konawe. Fakultas Perikanan dan Ilmu Kelautan Universitas Halu Oleo

Dedi, Effendy IJ, Balubi AM. 2017. Pertumbuhan populasi abalon Haliotis asinina yang dipelihara menggunakan drum plastik dengan kepadatan berbeda pada kawasan Integrated Multi Trophic Aquaculture (IMTA). Media Akuatika: Jurnal Ilmiah Jurusan Budidaya Perairan 1 (part 2) : 138-142

English S, Wilkinson C, Baker U. 1997. Survey manuals for tropical marine resources. Australia Institute of Marine Science. Townsville. Australia

Faturrahman, Rohyani IS, Sukiman, Hilman A. 2015. Pengaruh Kehadiran Hewan Pendamping Terhadap Abalon Halotis asinina Pada Sistem 
Multi Trophic Sea Farming. BioWallacea Jurnal Ilmiah Ilmu Biologi 1 (part 1) : 21-26

Fishbase. Gymnothorax thyrsoideus (Richardson, 1845). Dalam http://www.fishbase.org/summary/8252 (Di akses 13 Juni 2019, pukul 08.00)

Hayati H. 2017. Laju pertumbuhan kerang abalon Haliotis squamata melalui budidaya IMTA (Integrated Multi Trophic Aquaculture) di pantai geger, Nusa dua, kabupaten Badung, Bali [skripsi]. Bali: Fakultas Kelautan dan Perikanan, Universitas Udayana. 80 hal.

National Oceanic and Atmospheric Administration. 2008. Final white abalone recovery plan (haliotis sorenseni). National Marine Fisheries Service Office of Protected Resources

Odum, E.P. 1993. Dasar-dasar Ekologi. Terjemahan Tjahjono Samingan. Edisi Ketiga. Yogyakarta: Gadjah Mada University Press.

Odum, E.P. 1994. Dasar-Dasar Ekologi. Edisi Ketiga Gadjah Mada University Prees, Yogyakarta

Rani C. 2003. Perikanan dan terumbu karang yang rusak: Bagaimana Pengelolaannya?. Jurnal Bionatura 5 (Part 2) $97-111$

Riyanto M, Purbayanto A, Wiryawan B. 2016. Efektivitas penangkapan ikan kerapu macan (Epinephelus fuscoguttatus) dengan bubu menggunakan umpan buatan. Jurnal Harpodon Borneo. 4 (part 1) 2132

Rumahlatu, D, Gofhur A, Sutomo H. 2008. Hubungan faktor fisik-kimia lingkungan dengan keanekaragaman Echinodermata pada daerah pasang surut Pantai Kairatu. MIPA dan Pembelajarannya. 37 (part 1) $77-85$

Setiawan F. 2010. Panduan Lapangan Identifikasi Ikan Karang Dan Invertebrata Laut. Manado Sulawesi Utara. 314 hal

Setyono DED. 2009. Abalon: Biologi dan Reproduksi. Jakarta: LIPI Prss. 92 hal

Setyono, D.E.D 2010. Abalon: Teknologi Pembenihan. Jakarta: ISOI. 144 hal.

Suharti R. 2012. Hubungan kondisi terumbu karang dengan kelimpahan ikan chaetodontidae di pulau Karang Bongkok Kepulauan Seeribu [Thesis]. Jakarta: Program Pascasarjana, Universitas Terbuka. 180 hal 